\title{
Perceptions of Women and Men Leaders Following 360-Degree Feedback Evaluations
}

\author{
Lawrence A. Pfaff, EdD, Karyn J. Boatwright, PhD, Andrea L. Potthoff, \\ Caitlin Finan, Leigh Ann Ulrey, and Daniel M. Huber, PhD
}

$\mathrm{D}$ espite the fact that women have acquired a greater presence in corporate America in recent years, our society continues to associate leadership with "masculinity" (Dennis \& Kunkel, 2004; Kark, 2011; Yeagley, Subich, \& Tokar, 2010). People have tended to equate leadership with the completion of tasks such as decision making, assignment delegation, strategizing, and resource allocation, all of which are assumed to be men's strengths. Consequently, women, whose values of inclusion and connection are often devalued in our society, frequently are perceived to be less qualified for high-level leadership positions (Atwater, Brett, Waldman, DiMare, \& Hayden, 2004). These pervasive assumptions help explain why only $23 \%$ of women hold upper level executive positions (Catalyst, 2008; Eagly \& Carli, 2007b; U.S. Bureau of Labor Statistics, 2009).

According to Senge (2006), progressive organizations-for example Southwest Airlines (Gittell, 2003)-look favorably on relational employee-leader relationships and favor leaders who employ a combination of the stereotypical "masculine" task-oriented leadership behaviors and "feminine" relational leadership behaviors. This change is in response to employees' ideal leadership behavior preferences (Boatwright \& Forrest, 2000) and to improve the work environment, enhance worker satisfaction, and solidify organizational loyalty (Chin, 2004; Eagly \& Carli, 2007b; Fletcher, 2003, 2007; Gittell, 2011; Gittell \& Douglas, 2010; Powell, Butterfield, \& Parent, 2002; Raelin, 2003; Senge, 2006). This organizational paradigm shift, which now recognizes the importance of both task-oriented
In this study, researchers used a customized 360-degree method to examine the frequency with which 1,546 men and 721 women leaders perceived themselves and were perceived by colleagues as using 10 relational and 10 task-oriented leadership behaviors, as addressed in the ManagementLeadership Practices Inventory (MLPI). As hypothesized, men and women leaders, as well as their supervisors, employees, and peers, perceived women leaders to employ nine of the 10 relational leadership behaviors significantly more frequently than men leaders. Additionally, the employees' perceptions of their women leaders' use of task-oriented behaviors were significantly higher when compared to similar assessments from the employees of men leaders. However, the leaders as well as their supervisors and peers perceived men and women leaders' use of taskoriented behaviors as approximately equal. Broader implications of these findings are discussed. 
and relational behaviors, should provide increased opportunities for women to procure upper level leadership roles; however, women continue to encounter barriers when attempting to break through the "glass ceiling." Might women's lack of advancement into higher-level positions be due to the lingering perception that women may be exclusively relying on their relational behaviors and unable to employ the task-oriented behaviors that are also needed to succeed in higher-level positions? To what degree might this perception reflect reality? Do women in middlemanagement positions possess the task-oriented and relational leadership skills necessary for the more elite positions? Our aim in this study is to determine whether there are differences in the degree to which females and males perceive themselves and are perceived by colleagues, employees, and peers as employing relational and task-oriented leadership behaviors in the workplace.

\section{Relational and Task-Oriented Behaviors}

Relational and task-oriented behaviors, originally referred to as considerate and initiating structure, respectively (Halpin, 1957), are two widely used classifications for the observed behavior of leaders (Boatwright \& Forrest, 2000; Chin, 2004; Northouse, 2004). Relational behaviors include promoting mutual trust and collaboration; facilitating change; demonstrating concern for workers' needs; promoting teamwork; empowering employees to contribute to the workplace; demonstrating approachability; and encouraging healthy, respectful, and supportive working relationships. The leader's use of these relational behaviors is aimed at helping workers "feel comfortable with themselves, the [work] situation and each other" (Northouse, 2004, p. 3). In contrast, task-oriented behaviors include strategizing; organizing; assigning individual or group tasks; and demonstrating decisiveness, assertiveness, independence, and risk-taking behavior. Leaders use task-oriented behaviors to build a more efficient and productive work environment (Boatwright \& Forrest, 2000; Chin, 2004; Powell et al., 2002).

Because a balance of relational and task-oriented leadership behaviors is preferred by most employees (Boatwright \& Forrest, 2000) and is now more highly valued in the workplace, it is important to explore how potential leaders may develop these behaviors. For women, the process of gender role socialization may foster the development of both sets of leadership behaviors (Fletcher, 2007; McAlpine, 2009). More specifically, many women are encouraged to build their self-concepts on interdependent connectedness with others, leading to the development of "feminine" relational skills (Fletcher, 2007). Additionally, to prepare for career success that includes acquiring a leadership role, many young, relationally oriented females are implicitly encouraged by parents, teachers, peers, and the media to develop "masculine" task-oriented behaviors (e.g., Eagly \& Chin, 2010). Conversely, young males are typically encouraged to develop 
gender-congruent, "masculine," task-oriented behaviors, but are less frequently encouraged to refine their gender-incongruent, "feminine" relational behaviors (Eagly \& Carli, 2007a). Due to these differences in the socialization processes, women, more so than men, may possess both sets of skills deemed critical for higher-level leadership positions.

Differences in the leadership styles, personality traits, and work outcomes of women and men in leadership roles have received a significant amount of scholarly and empirical attention in the past few decades (e.g., Eagly \& Chin, 2010; Fletcher, 2007; Kark, 2011). As previously discussed, attention has been also devoted to the study of relational and task-oriented leadership and the ways in which these behaviors affect the work environment (Eagly \& Carli, 2007a; Powell et al., 2002). However, Eagly (2005) points out that, "although there is general agreement that women face more barriers to becoming leaders than men do, especially for leader roles that are male-dominated, there is much less agreement about the behavior of women and men once they attain such roles" (p. 279). Few researchers have examined the extent to which men and women leaders perceive themselves and are perceived by colleagues as employing relational and task-oriented leadership behaviors in the workplace. Because perceptions of women's leadership behaviors "may affect people's views about whether women should become leaders and advance to higher positions in organizational hierarchies" (Eagly, 2005, p. 279) and have not received adequate attention, this study attempts to determine whether women leaders are perceived to demonstrate this critical set of leadership behaviors by themselves, employees, peers, and supervisors to demonstrate this critical set of leadership behaviors as frequently as their men counterparts.

To address this critical gap in the gender research, the current study employed the 360-degree method to assess the gender differences in selfperceptions as well as the perceptions of the direct supervisors, immediate employees, and peers of 2,267 men and women leaders from 204 organizations scattered throughout the United States. Because women are more encouraged than men to develop their relational skills, the present authors hypothesized that women leaders will perceive themselves and be perceived by others as employing relational leadership behaviors significantly more than men leaders. Additionally, because both women and men who aspire for leadership positions are encouraged to develop task-oriented skills, the authors also hypothesized that men and women leaders' use of task-oriented behaviors will be perceived as equal. Specifically, the researchers hypothesize that an analysis of the data will reveal the following:

1. Women leaders' use of relational leadership behaviors will be greater than men leaders' use of relational leadership behaviors as evaluated by self-reports.

2. Women leaders' use of task-oriented leadership behaviors will be equal to men leaders' use of task-oriented leadership behaviors as evaluated by self-reports. 
3. Women leaders' use of relational leadership behaviors will be greater than men leaders' use of relational leadership behaviors as evaluated by their respective supervisors.

4. Women leaders' use of task-oriented leadership behaviors will be equal to men leaders' use of task-oriented leadership behaviors as evaluated by their respective supervisors.

5. Women leaders' use of relational leadership behaviors will be greater than men leaders' use of relational leadership behaviors as evaluated by their respective direct employees.

6. Women leaders' use of task-oriented leadership behaviors will be equal to men leaders' use of task-oriented leadership behaviors as evaluated by their respective direct employees.

7. Women leaders' use of relational leadership behaviors will be greater than men leaders' use of relational leadership behaviors as evaluated by their respective peers.

8. Women leaders' use of task-oriented leadership behaviors will be equal to men leaders' use of task-oriented behaviors as evaluated by their respective peers.

\section{Method}

\section{Participants}

Usable surveys were obtained from 15,244 participants who were employed in 204 retail, production, business, and banking organizations across the United States. The leader sample included 2,267 lower-level, midlevel, and higher-level managers and supervisors who were between 24 and 75 years old ( $M=38$ years). Consistent with national trends (U.S. Bureau of Labor Statistics, 2009), 1,546 (68\%) of the leaders were men and 721 (32\%) were women. Ninety-three percent of leaders were EuropeanAmerican, 3\% were Asian American, 2\% were African American, and $2 \%$ opted not to disclose their ethnic background. Surveys were also obtained from 1,674 of the leaders' immediate supervisors (80\% men; $20 \%$ women), 8,708 employees (55\% men), and 2,595 peers ( $68 \%$ men). To ensure that the participants felt sufficiently secure in completing these evaluations, the first author did not ask participants to include additional demographic data. Therefore, data related to the ethnicity and age of the participants were not obtained from the nonleader participants.

\section{Measures}

The Management-Leadership Practices Inventory (MLPI; Pfaff, 1989, 1995 ) is a 360-degree instrument, available in a hard copy or an online version, designed to assess a leader's relational and task-oriented behaviors (see Appendix of this article). Each of the 85 items on the four versions of the MLPI is tailored to apply to leaders, immediate supervisors, direct employees, or peers. For example, a leader rates how frequently he or she 
displays particular leadership behaviors (e.g., "I give frequent praise for an employee's good work") and supervisors, employees, and peers rate how frequently they believe the identified leader displays these same behaviors (e.g., "This leader gives frequent praise to his or her employees for good work"). Participants rate items on a 7-point Likert scale: A score of 1 indicates that the statement is "never true" and a score of 7 indicates that the statement is "always true."

Through a factorial analysis, these 20 relational and task-oriented leadership behaviors were extracted from a larger set of factors originally drawn from an extensive review of the leadership measurement literature. Each of the 20 factors is measured by a participant's average response to several items associated with that particular factor (Pfaff, 1989). The 10 relational leadership behaviors assessed in the MLPI include: communicating verbally with employees, promoting teamwork, empowering employees, building trust, coaching, facilitating change, delegating responsibilities, encouraging participation of employees in decisions, recognizing the achievement of employees, and demonstrating approachability. Examples of items measuring these behaviors include: "This leader helps employees understand how their work relates to the organization's goals," "This leader helps people learn new skills," and "This leader gives frequent praise for good work." The 10 task-oriented behaviors include: goal setting, planning, demonstrating technical expertise, setting performance standards, delegation of specific tasks, strategizing, evaluating workers' performance, resourcefulness, selfconfidence, and decisiveness. Examples of items measuring these behaviors include: "[This leader] Lets people know when results are not up to expectations" and "[This leader] Makes timely decisions."

Initial validation data were collected from 445 managers or leaders and 924 of their direct employees $(N=2,369)$. The internal reliability of the 20 factors ranged between .76 and .92 (Pfaff, 1995). Content validity, face validity, and independence of the two factors have been verified via a thorough review of the management literature. In the current study, internal reliability coefficients for the relational and task-oriented leadership items were .95 and .94, respectively, which were consistent with previous studies (e.g., Schullery, Schullery, Knudstrup, \& Pfaff, 2009).

\section{Procedure}

Within each of the 204 organizations, the first author distributed MLPI questionnaires (Appendix A) to participants as part of his professional consulting services. The leaders and their supervisors, direct employees, and peers were strongly encouraged to complete the instrument as part of their professional obligations and were asked to sign separate consent forms. At the beginning of the questionnaire, the participants were informed that, "This inventory contains a series of statements that describe what managers do. Answer each item about the person whose name appears on the front page. Circle the number ( 1 to 7 ) to the right of each item which best describes the way he/she behaves as a manager." 
Participants were granted anonymity. Following the analysis of the surveys within each organization, the first author provided feedback and strategic interventions to leaders as part of a leadership workshop to improve the overall quality of the workplace.

\section{Results}

A series of independent sample $t$-tests was used to determine whether ratings of men and women leaders differed significantly on each of the 20 dimensions of leadership behavior. To reduce the probability of Type I error for the current study, a conservative significance level of $p<.005$ was used. For means, standard deviations, $t$-scores, and level of significance for analyses testing leaders' behaviors by leaders themselves, supervisors, employees, and peers, see Table 1.

\section{Leaders' Self-Evaluations}

The first hypothesis that women leaders' assessments of their own use of the 10 relational leadership behaviors would be significantly higher than men leaders' assessments was partially supported. In support of Hypothesis 1, women leaders' self-assessments were significantly higher in seven of the 10 relational leadership skills: (1) encouraging teamwork $(t(2265)=4.27, p<.001)$, (2) empowering employees $(t(2265)=3.53$, $p<.001)$, (3) coaching employees $(t(2265)=4.48, p<.001)$, (4) facilitating change $(t(2265)=5.25, p<.001)$, (5) encouraging employee participation $(t(2265)=3.94, p<.001)$, (6) showing recognition to employees $(t(2265)=6.12, p<.001)$, and (7) demonstrating approachability $(t(2265)$ $=4.34, p<.001)$. In contrast to Hypothesis 1 , there were no significant differences between self-assessments for (1) communicating verbally with employees, (2) promoting trust, and (3) delegating specific tasks.

The second hypothesis, that women leaders' self-assessments of the 10 task-oriented leadership behaviors would be equal to the men leaders' assessments, was also partially supported. Women and men leaders' self-assessments were similar in five of the 10 dimensions: (1) technical expertise, (2) directiveness, (3) strategizing, (4) self-confidence, and (5) decisiveness. Contrary to expectations, women's self-ratings were significantly higher than men's self-ratings on the remaining five dimensions: (1) goal setting $(t(2265)=2.92, p<.005)$, (2) planning and organizing $(t(2265)=3.58, p<.001)$, (3) setting performance standards $(t(2265)=$ $5.34, p<.001)$, (4) evaluating employees $(t(2265)=5.52, p<.001)$, and (5) resourcefulness $(t(2265)=2.84, p<.005)$.

\section{Supervisors' Evaluations}

For Hypothesis 3, we predicted that direct supervisors would rate women leaders' use of relational leadership behaviors as significantly higher than the direct supervisors of men leaders. Hypothesis 3 was partially supported, as 


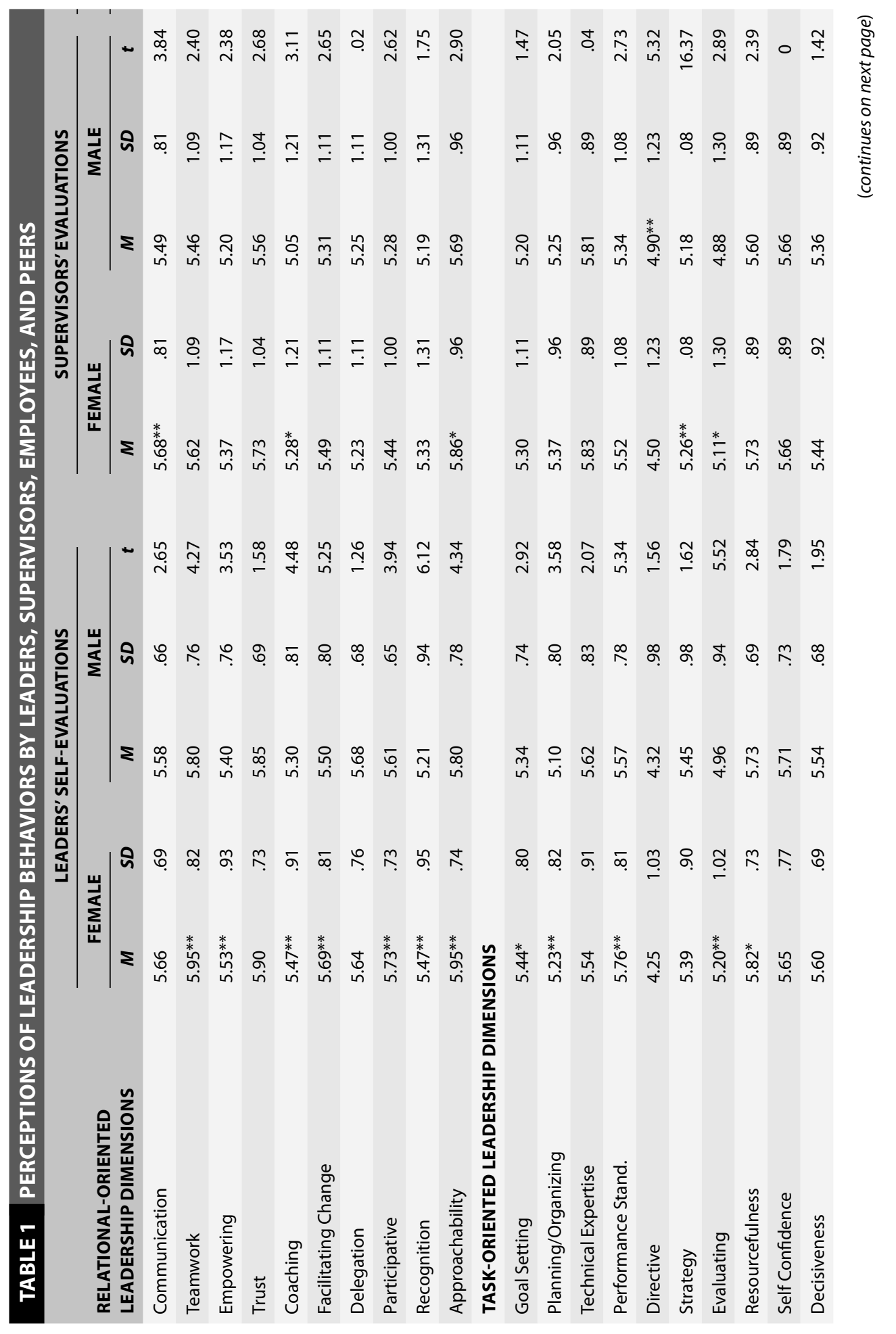




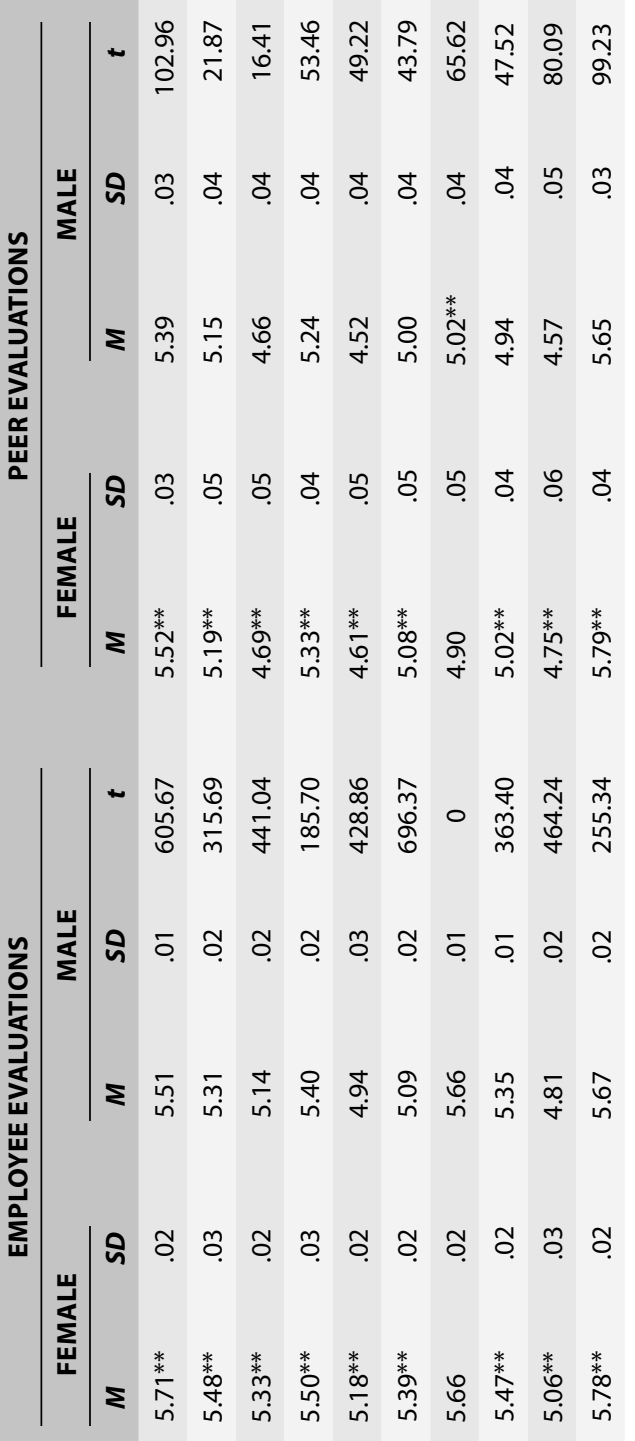

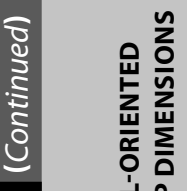




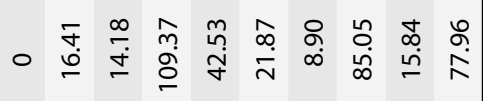

ఫ. ఫ

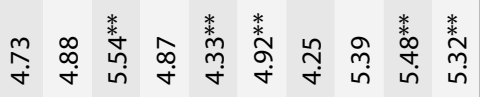

贻

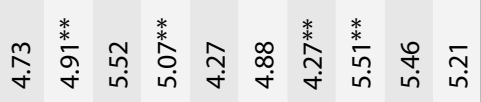

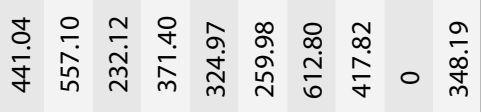

กิ

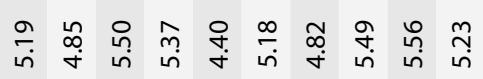

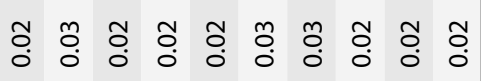

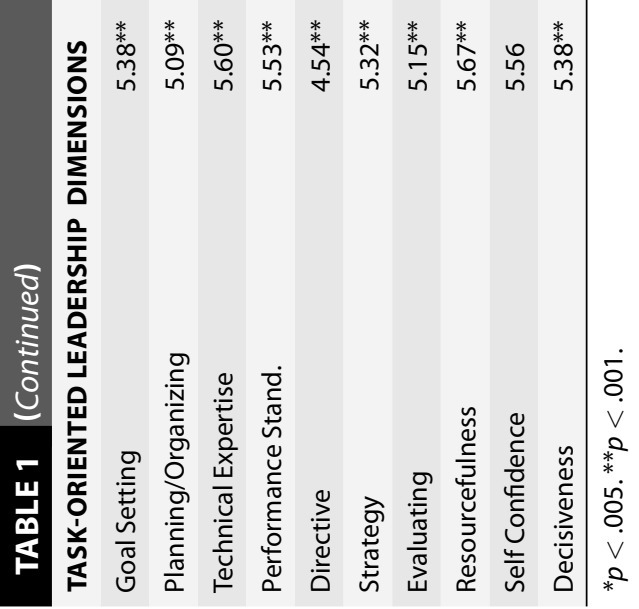


the direct supervisors rated women leaders higher on the following three behaviors: (1) communicating verbally with employees $(t(1672)=3.84$, $p<.001)$, (2) coaching employees $(t(1672)=3.11, p<.005)$, and (3) being approachable $(t(1672)=2.90, p<.005)$. Contrary to expectations, there were no significant differences for the following seven dimensions: (1) teamwork, (2) empowering employees, (3) trust, (4) facilitating change, (5) delegation, (6) participation, and (7) recognition.

The fourth hypothesis, that the direct supervisors of women leaders would assess women leaders' use of task-oriented leadership behaviors as similar to their men counterparts, was mostly supported. There were non-significant findings for supervisors' assessments on taskoriented behaviors for seven dimensions: (1) goal setting, (2) planning and organizing, (3) technical expertise, (4) setting performance standards, (5) resourcefulness, (6) self-confidence, and (7) decisiveness. In contrast to Hypothesis 4, supervisors rated females significantly higher for strategizing $(t(1672)=16.37, p<.001)$ and evaluating employees $(t(1672)=$ $2.89, p<.005)$, whereas they rated males significantly higher for directiveness $(t(1672)=5.32, p<.001)$.

\section{Employees' Evaluations}

The fifth hypothesis concerning women leaders' direct employees rating their leaders' use of relational leadership behaviors as significantly higher than those of men leaders was mostly supported. Consistent with Hypothesis 5, direct employees rated women leaders as engaging in relational leadership behavior more frequently on nine dimensions: (1) communicating with employees $(t(8706)=605.67, p<.001)$, (2) promoting teamwork $(t(8706)=315.69, p<.001)$, (3) empowering employees $(t(8706)=441.04, p<.001)$, (4) fostering trust $(t(8706)=185.70$, $p<.001)$, (5) coaching employees $(t(8706)=428.86, p<.001)$, (6) facilitating change $(t(8706)=696.37, p<.001)$, (7) participating $(t(8706)=$ $363.40, p<.001)$, (8) showing recognition $(t(8706)=464.24, p<.001)$, and (9) demonstrating approachability $(t(8706)=255.34, p<.001)$. In contrast to what was unexpected, there was no difference for employees' ratings on delegating specific tasks.

The sixth hypothesis, that women leaders' direct employees would rate women leaders' use of task-oriented leadership behaviors as equal to men leaders' behaviors, was supported for one dimension: demonstrating self-confidence. In contrast to what we predicted, employees rated women leaders' use of nine of these task-oriented skills as more frequent: (1) goal setting $(t(8706)=441.04, p<.001)$, (2) planning and organizing $(t(8706)=557.10, p<.001),(3)$ technical expertise $(t(8706)=232.12$, $p<.001)$, (4) setting performance standards $(t(8706)=371.40, p<$ $.001)$, (5) providing direct communication $(t(8706)=324.97, p<.001)$, (6) ability to strategize $(t(8706)=259.98, p<.001)$, (7) evaluating employees $(t(8706)=612.80, p<.001)$, (8) resourcefulness $(t(8706)=417.82$, $p<.001)$, and (9) decisiveness $(t(8706)=348.19, p<.001)$. There was not 
a difference, however, for employees' perspectives of leaders' use of selfconfidence building behaviors. Employees perceived female's leadership behavior as higher than males on more dimensions than the other three evaluators (i.e., self, supervisor, and peer).

\section{Peers' Evaluations}

The seventh hypothesis, that peers would rate women leaders' use of relational leadership behaviors as significantly more frequent than the men leaders' behaviors, was partially supported. Specifically, peers rated women leaders as using the following nine skills more frequently than males' leadership dimensions: (1) communicating with employees $(t(2593)=102.96, p<.001),(2)$ promoting teamwork $(t(2593)=21.87$, $p<.001)$, (3) empowering employees $(t(2593)=16.41, p<.001)$, (4) fostering trust $(t(2593)=53.46, p<.001)$, (5) coaching employees $(t(2593)=49.22, p<.001),(6)$ facilitating change $(t(2593)=43.79$, $p<.001)$, (7) participating $(t(2593)=47.52, p<.001)$, (8) showing recognition $(t(2593)=80.09, p<.001)$, and (9) demonstrating approachability $(t(2593)=99.23, p<.001)$. Contrary to expectations, peers rated male leaders as delegating specific tasks more frequently than females $(t(2593)$ $=65.62, p<.001$ ).

The eighth hypothesis, that women leaders' peers would rate women leaders' use of task-oriented leadership behaviors as equal to men leaders' behaviors, was supported on one dimension: goal setting. Based on peers' ratings, males in leadership positions more frequently use five task-oriented leadership skills: (1) demonstrating technical expertise $(t(2593)=14.18, p<.001),(2)$ being directive $(t(2593)=42.53, p<.001)$, (3) using strategic techniques $(t(2593)=21.87, p<.001)$, (4) demonstrating self-confidence $(t(2593)=15.84, p<.001)$, and (5) being decisive $(t(2593)$ $=77.96, p<.001)$. In contrast, peers perceive women leaders as using the following skills more often: (1) planning and organizing $(t(2593)=$ $16.41, p<.001)$, (2) setting performance standards $(t(2593)=109.37$, $p<.001)$, (3) evaluating $(t(2593)=8.90, p<.001)$, and (4) being resourceful $(t(2593)=85.05, p<.001)$.

\section{Discussion}

Although women have made impressive progress in acquiring an increasing percentage of middle-management leadership positions within North American organizations, they still only hold 23\% of upper level executive positions in the United States (U.S. Bureau of Labor Statistics, 2009) and 8\% of Fortune 500 chief executive positions (Helfat, Harris, \& Wolfson, 2006). These low statistics suggest that many women middle managers who aspire to break the proverbial "glass ceiling" either face sociocultural barriers or simply do not possess the necessary leadership behaviors to warrant advancement into the elite positions. Because 
progressive organizations consistently report an interest in hiring leaders capable of employing both relational and task-oriented leadership behaviors, might the small percentage of women at the top be due to a shortage of promotable women middle managers who possess both sets of behaviors?

Our research aimed to answer this question by comparing the frequency with which 2,267 men and women lower level and middle managers self-reported or were perceived to have employed the 10 relational and 10 task-oriented behaviors deemed critical for effective leadership. Although prior research has also examined gender and leadership behaviors (e.g., Bartol, Martin, \& Kromkowski, 2003), the present study extends previous findings by including the perceptions of the leaders themselves,

Our analysis of the data showed that women managers evaluated themselves and were evaluated by their immediate supervisors, direct employees, and peers as employing nine of the 10 relational leadership behaviors more frequently than men

leaders. their direct supervisors, peers, and employees. Our analysis of the data showed that women managers evaluated themselves and were evaluated by their immediate supervisors, direct employees, and peers as employing nine of the 10 relational leadership behaviors more frequently than men leaders.

The socialization processes that influence women and men throughout their lives provide one explanation for the observed findings. Relational theorists (e.g., Fletcher, 2007), for example, contend that young girls receive explicit and implicit encouragement from parents, teachers, and peers to build their identities within the relational context of interpersonal connections. These constant messages foster the development of relational behaviors, which women subsequently infuse into their leadership styles (Fletcher, 2007). Conversely, because these traits are culturally conceptualized as "feminine" and deemed "weaknesses ... that need to be overcome in order to make it in the 'real' world," many men are "socialized to devalue and deny in themselves the relational skills needed to survive psychologically ... (and instead) rely on women to provide these attributes" (Fletcher, 1999, p. 9). As a result, a significant portion of men leaders who have received less-explicit encouragement to hone these relational skills may be less prepared to utilize these behaviors in the workplace, despite receiving encouragement to do so by their employees or supervisors. Although not empirically supported through recent research, many contemporary organizations now purport to want leaders with a balanced leadership style (Senge, 2006), that is, leaders who can supplement their traditional task-oriented behaviors with relational skills. If organizational rhetoric matches organizational practices, men and women may be more apt to climb the proverbial leadership ladder if they are encouraged to develop both their task-oriented and relationally oriented leadership behaviors. Furthermore, educators interested in developing their students' leadership potential must emphasize the development of historically devalued relational skills. 
Another viable explanation for our results may be the biased perceptions of the participants. Specifically, some studies suggest that people are more likely to expect men and women to act in ways that conform to gender-specific stereotypes (e.g., Eagly \& Karau, 2002). Therefore, one could argue that the cultural expectations that women $d o$ and should possess stronger relational traits predisposed participants to notice women's relational behaviors more than men's. This same argument, however, would also cause one to expect participants to report that men leaders employed the "masculine" task-oriented behaviors significantly more than women leaders. As hypothesized, however, women and men leaders were perceived as fairly equal in utilizing these more traditional behaviors in the workplace.

Traditional leadership models have included an assortment of taskoriented behaviors such as goal setting, planning, strategizing, evaluating, and making critical decisions (Atwater et al., 2004; Dennis \& Kunkel, 2004). Historically, these task-oriented behaviors have been associated with "masculinity," which suggests that men are expected to employ these leadership behaviors with greater frequency than women. Interestingly, however, employees' perceptions of their women managers' use of nine of the 10 task-oriented behaviors were significantly higher than employees' perceptions of men managers' use of these skills. Though unexpected, our findings are consistent with studies showing that employees of women lower level supervisors, middle managers, and executives rate their leaders higher in the degree to which they employ task-oriented behaviors than the employees of men leaders (Bartol et al., 2003). Furthermore, our results revealed that the degree to which women midlevel leaders perceive themselves as demonstrating task-oriented behaviors is higher than self-reports from men leaders. Finally, women and men middle managers are perceived by their supervisors and peers as employing task-oriented leadership behaviors with similar frequencies.

If task-oriented behaviors are deemed "masculine," why did employees and a substantial portion of women leaders rate themselves or their women middle managers higher in nine and five of the 10 task-oriented leadership behaviors, respectively? A sociocultural explanation for these findings is that parents, coaches, mentors, and teachers of young girls may have emphasized the importance of developing the "masculine" taskoriented behaviors for obtaining success in their future careers. Richie and colleagues' (1997) findings that high-achieving African American women reported they had intentionally developed gender-incongruent behaviors. Clearly, the demanding process of developing "feminine" relational skills as well as traditional "masculine" traits deemed critically important for success could have predisposed the women leaders in our study to develop a more balanced leadership style.

Limitations in this study must be noted. First, the primary goal was to assess gender differences in objective leadership behaviors observed in the workplace. Thus, our data did not evaluate the effectiveness of these leadership behaviors but only the extent to which they were perceived by the leaders themselves and by their supervisors, peers, and direct employees. Second, 
our sample was limited due to its homogenous makeup of predominantly European-American managers. This lack of diversity restricts the generalizability of our findings to leaders from different ethnic backgrounds. A similar 360-degree study using a more diverse ethnic sample may yield different results. And last, one of our strengths, a large number of participants across 204 organizations, could also be a limitation in that small differences more frequently are found to be statistically significant. More studies are needed to assess the practical implications of the gender differences.

When asked to describe their "ideal" leader, many employees express a preference for individuals who employ both relational and taskoriented behaviors (Boatwright \& Forrest, 2000). Additionally, organizations increasingly believe that these multidimensional leaders may help to improve the work environment, worker satisfaction, and organizational loyalty. Thus, the present findings are noteworthy because they highlight that middle-management women employ both sets of leadership behaviors and should be strongly considered for upper-level positions.

In sum, organizations have made extraordinary progress toward increased gender equality in leadership positions. Still, the advancement of women into elite positions of authority has been disappointingly less than expected and does not seem to be improving significantly (Eagly \& Carli, 2007b). One sociocultural threat to equality within the higher-level leadership roles may be the lingering conscious or subconscious assumption that organizations should hire or promote men and women who predominantly display "masculine" or task-oriented behaviors (Atwater et al., 2004; Powell et al., 2002). In the past two decades, however, organizations have been "encouraged-even warned-to reinvent themselves, push decision making to lower levels, encourage teamwork and collaboration, flatten the hierarchy, and think systemically. . . Organizations are being exhorted in increasingly stronger terms to adopt new models of success and develop new skills in their workers" (Fletcher, 1999, p. 113). In other words, organizations now feel pressured to hire leaders who can supplement their traditional task-oriented behaviors with relational behaviors. Our analysis demonstrated that the small percentage of women executive leaders is not due to limited human resources. In fact, our findings strongly reveal that a significant number of women middle managers are perceived as being behaviorally prepared for advancement into the elite leadership positions. Not only do they possess an equal or greater number of traditional task-oriented behaviors but they also employ the relational skills deemed necessary by organizations to construct these "new models of success."

\section{Acknowledgment}

This research was supported by the Stephanie Vibbert Women's Leadership Research Center endowment. 


\section{References}

Atwater, L.E., Brett, J.F., Waldman, D., DiMare, L., \& Hayden, M.V. (2004). Men's and women's perceptions of the gender typing of management subroles. Sex Roles, 50, 191-199.

Bartol, K.M., Martin, D.C., \& Kromkowski, J.A. (2003). Leadership and the glass ceiling: Gender and ethnic group influences on leader behaviors at middle and executive managerial levels. The Journal of Leadership and Organizational Studies, 9, 8-19.

Boatwright, K.J., \& Forrest, L. (2000). Leadership preferences: The influence of gender and needs for connection on workers' ideal preferences for leadership behaviors. The Journal of Leadership and Organizational Studies, 7, 18-34.

Catalyst. (2008). Census of women corporate officers and top earners. New York, NY: Catalyst. Retrieved from http://www.catalyst.org.

Chin, J.L. (2004). Feminist leadership: Feminist visions and diverse voices. Psychology of Women Quarterly, 28, 1-8.

Dennis, M.R., \& Kunkel, A.D. (2004). Perceptions of men, women, and CEOs: The effects of gender identity. Social Behavior and Personality, 32(2), 155-172.

Eagly, A. (2005). Women and men as leaders. In J. Antonakis, A.T. Cianciolo, \& R.J. Sternberg (Eds.), The nature of leadership (pp. 279-301). Thousand Oaks, CA: Sage.

Eagly, A.H., \& Carli, L.L. (2007a). The female leadership advantage: An evaluation of the evidence. Leadership Quarterly, 14, 807-834.

Eagly, A.H., \& Carli, L.L. (2007b). Through the labyrinth: The truth about how women become leaders. Boston, MA: Harvard University Press.

Eagly, A.H., \& Chin, J.L. (2010). Diversity and leadership in a changing world. American Psychologist, 65, 216-224.

Eagly, A.H., \& Karau, S.J. (2002). Role congruity theory of prejudice toward female leaders.

Fletcher, J. (2003). The different faces of feminist leadership. Paper presented at the Annual Meeting of the American Psychological Association, Toronto, Canada.

Fletcher, J.K. (1999). Disappearing acts: Gender, power, and relational practice at work. Cambridge, MA: MIT Press.

Fletcher, J.K. (2007). Leadership, power, and positive relationships. In J.E. Dutton \& B.R. Ragins (Eds.), Exploring positive relationships at work: Building a theoretical and research foundation (pp. 347-371). Mahwah, NJ: Lawrence Erlbaum Associates.

Gittell, J.H. (2003). The Southwest Airlines way: Using the power of relationships to achieve high performance. New York, NY: McGraw-Hill.

Gittell, J.H. (2011). New directions for relational coordination theory. In K. Cameron \& G. Spreitzer (Eds.), Oxford handbook of positive organizational scholarship. Oxford, England: Oxford University Press.

Gittell, J.H., \& Douglas, A. (2010). Relational bureaucracy: On the boundary of relational and bureaucratic organizing. Unpublished manuscript.

Halpin, A.W. (1957). Manual for the Leader Behavior Description Questionnaire. Center for Business Research, College of Commerce and Administration. Columbus, $\mathrm{OH}$ : Ohio State University.

Helfat, C.E., Harris, D., \& Wolfson, P.J. (2006). The pipeline to the top: Women and men in the top executive ranks of U.S. corporations. Academy of Management Perspectives, 20(4), 42-64.

Kark, R. (2011). Workplace intimacy in leader-follower relationships. In K. Cameron \& G. Spreitzer (Eds.), Oxford handbook of positive organizational scholarship (pp. 423-438). Oxford, England: Oxford University Press.

McAlpine, K.L. (2009). Women and leadership: A qualitative analysis of female CEOs of Fortune 500 companies. Unpublished manuscript, Kalamazoo College, Kalamazoo, MI.

Northouse, P. G. 2004. Leadership: Theory and practice. Thousand Oaks, CA: Sage.

Pfaff, L.A. (1989). Management-Leadership Practices Inventory. Portage, MI: Author.

Pfaff, L.A. (1995). MLPI psychometrics. Unpublished manuscript.

Powell, G.N., Butterfield, D.A., \& Parent, J.D. (2002). Gender and managerial stereotypes: Have the times changed? Journal of Management, 28, 177-193. 
Raelin, J. (2003). Creating leaderful organizations: How to bring out leadership in everyone. San Francisco, CA: Berrett-Koehler.

Ritchie, B.S., Fassinger, R.E., Linn, S.G., Johnson, J., Prosser, J., \& Robinson, S. (1997). Persistence, connection, and passion: A qualitative study of the career development of highly achieving African American-black and white women. Journal of Counseling Psychology, 44, 133-148.

Schullery, N.M., Schullery, S.E., Knudstrup, P., \& Pfaff, L.A. (2009). The relationship between personality type and 360-degree evaluation of management skills. Journal of Psychological Type, 69(11), 141-155.

Senge, P.M. (2006). The fifth discipline: The art and practice of the learning organization (2nd ed.). London, England: Random House.

U.S. Bureau of Labor Statistics. (2009, January). Household data annual averages: Employed persons by detailed occupation, sex, race, and Hispanic or Latino ethnicity. Retrieved from http://www.bls.gov/cps/cpsaat11.pdf

Yeagley, E.E., Subich, L.M., \& Tokar, D.M. (2010). Modeling college women's perceptions of elite leadership positions with Social Cognitive Career Theory. Journal of Vocational Behaviors, 66, 304-325.

\section{LAWRENCE A. PFAFF}

Lawrence A. Pfaff, EdD, is professor of psychology at Spring Arbor University in Michigan where he teaches undergraduate psychology and graduate counseling. He has also done a great deal of work in the area of survey development, utilization, and validation. He has published assessment instruments in the areas of leadership, professional communication, teams' effectiveness, career interest, and time management. He has also consulted extensively in the areas of management and leadership development, organizational needs assessment, executive coaching, and behavioral selection techniques and systems. He is a member of the American Psychological Association and the Society for Industrial and Organizational Psychology. He holds master's and doctoral degrees in counseling psychology and a bachelor's degree in physics. E-mail: lpfaff@arbor.edu

\section{KARYN J. BOATWRIGHT}

Karyn J. Boatwright graduated from Michigan State University with a PhD in counseling psychology. Currently, she teaches several courses in the psychology and women's studies department at Kalamazoo College. Her major research interests include women's leadership aspirations, workers' leadership preferences, and feminist pedagogy. E-mail: Karyn.Boatwright@kzoo.edu 
Andrea L. Potthoff received a BA from Kalamazoo College and is a graduate student in the University of Houston's clinical psychology PhD program. Her current research focuses on moderators of the relation between abuse and commitment in victims of intimate partner violence, with particular interest in victims' implicit beliefs about relationships. In addition, she is also interested in the efficacy of brief marital interventions targeting mildly distressed couples. She hopes to enter academia after completing graduate school.

E-mail: andrea.lynn.potthoff@gmail.com

\section{CAITLIN FINAN}

Caitlin Finan aided in this research project during her time as an undergraduate student at Kalamazoo College. She currently works in the University of Michigan Health System, where she is involved in several research projects relating to newborn screening and to patient-provider communication in health care settings.

E-mail: ccfinan@gmail.com

\section{LEIGH ANN ULREY}

Leigh Ann Ulrey graduated from Kalamazoo College in 2010 and currently works for AmeriCorps in Detroit, MI.

E-mail: Leigh.Ulrey07@kzoo.edu

\section{DANIEL M. HUBER}

Daniel M. Huber completed his $\mathrm{PhD}$ in counseling psychology from Western Michigan University in 2010. He currently works as a staff psychologist within the posttraumatic stress disorder program and substance abuse clinic at the Albany Stratton Veterans Affairs Medical Center in Albany, NY. In addition to clinical services, he serves on the training committee for the Albany Psychology Internship Consortium. His primary areas of research involve attachment orientation, mental health among veterans, posttraumatic stress disorder, and training students in research and practice.

E-mail: Daniel.Huber@va.gov 


\section{Appendix: The Management Leadership Practices Inventory (MLPI)}

This inventory is being completed about

My relationship to person named above is: (check one) I report to the person named I supervise the person named I am a peer/colleague of the person named I am the person named

\section{Instructions}

This inventory contains a series of statements that describe what managers do. Answer each item about the person whose name appears on the front page. Circle the number ( 1 to 7 ) to the right of each item that best describes the way he/she behaves as a manager.

To guide you:

" 1 " means that the statement is true virtually never, or not at all. " 4 " means that the statement is true about half of the time, or sometimes.

"7" means that the statement is true virtually always, or without fail.

Of course, you may use the other numbers:

" 3 " and " 2 " to represent varying degrees between sometimes and never.

" 5 " and " 6 " to represent varying degrees between sometimes and always.

Copyright 1989, 1991, 2006 Lawrence A. Pfaff 
Circle only one number for each statement. Do not circle between numbers.

Try to complete all statements. There is no time limit. There are no right or wrong answers. Answer as accurately and honestly as you can. If you cannot answer an item, leave it blank.

If you report to the person named on the front page, or are his/ her peer, your responses will remain anonymous.

Remember: Mark each statement "1" (never) to "7" (always) based on how accurately you feel it describes the person named on the front page.

This person:

1. Makes sure people know what they are expected to do before they begin

2. Allows individuals to direct their own activities

3. Understands the technical aspects of the work

4. Asks for employee input

5. Clearly communicates the strategy and direction of the unit

6. Makes sure people are properly trained for their job

7. Supervises workers closely

8. Organizes and coordinates the work of the unit

9. Tells people when plans change to meet changing demands

10. Encourages people to perform at high levels

11. Permits others to take responsibility into their own hands

12. Sets challenging goals for the group

13 Rewards those who deserve it

14. Knows how to get things done

15. Gives frequent feedback on performance

16. Informs people immediately when goals and expectations change

17. Promotes cooperation among employees

18. Makes sure people have sufficient authority to accomplish objectives

19. Promotes a climate of trust

20. Acts decisively when necessary

21. Makes plans that help get the work done the best way possible

22. Makes changes as a result of employee input

23. Is easy to talk to about work problems

\begin{tabular}{cccccccc} 
Never & \multicolumn{4}{c}{ Sometimes } & \multicolumn{2}{c}{ Always } \\
1 & 2 & 3 & 4 & 5 & 6 & 7 \\
1 & 2 & 3 & 4 & 5 & 6 & 7 \\
1 & 2 & 3 & 4 & 5 & 6 & 7 \\
1 & 2 & 3 & 4 & 5 & 6 & 7 \\
1 & 2 & 3 & 4 & 5 & 6 & 7
\end{tabular}

$\begin{array}{lllllll}1 & 2 & 3 & 4 & 5 & 6 & 7\end{array}$

$\begin{array}{lllllll}1 & 2 & 3 & 4 & 5 & 6 & 7\end{array}$

$\begin{array}{lllllll}1 & 2 & 3 & 4 & 5 & 6 & 7\end{array}$

$\begin{array}{lllllll}1 & 2 & 3 & 4 & 5 & 6 & 7\end{array}$

$\begin{array}{lllllll}1 & 2 & 3 & 4 & 5 & 6 & 7\end{array}$

$\begin{array}{lllllll}1 & 2 & 3 & 4 & 5 & 6 & 7\end{array}$

$\begin{array}{lllllll}1 & 2 & 3 & 4 & 5 & 6 & 7\end{array}$

$\begin{array}{lllllll}1 & 2 & 3 & 4 & 5 & 6 & 7\end{array}$

$\begin{array}{lllllll}1 & 2 & 3 & 4 & 5 & 6 & 7\end{array}$

$\begin{array}{lllllll}1 & 2 & 3 & 4 & 5 & 6 & 7\end{array}$

$\begin{array}{lllllll}1 & 2 & 3 & 4 & 5 & 6 & 7\end{array}$

$\begin{array}{lllllll}1 & 2 & 3 & 4 & 5 & 6 & 7\end{array}$

$\begin{array}{lllllll}1 & 2 & 3 & 4 & 5 & 6 & 7\end{array}$

$\begin{array}{lllllll}1 & 2 & 3 & 4 & 5 & 6 & 7\end{array}$

$\begin{array}{lllllll}1 & 2 & 3 & 4 & 5 & 6 & 7\end{array}$

$\begin{array}{lllllll}1 & 2 & 3 & 4 & 5 & 6 & 7\end{array}$

$\begin{array}{lllllll}1 & 2 & 3 & 4 & 5 & 6 & 7\end{array}$

$\begin{array}{lllllll}1 & 2 & 3 & 4 & 5 & 6 & 7\end{array}$ 
Remember: Mark each statement "1" (never) to "7" (always) based on how accurately you feel it describes the person named on the front page.

This person:

24. Coaches people to help them improve their performance

25. Communicates regularly with staff

26. Gives recognition for achieving goals

27. Communicates goals effectively to the entire unit

28. Gets tasks accomplished, no matter how difficult

29. Exercises tight control over the work group

30. Delegates responsibility for getting the work done

31. Inspires people to do their best

32. Has confidence in people

33. Has a positive attitude

34. Listens to people

35. Informs key people of necessary changes

36. Lets people know when results are not up to expectations

37. Knows what is necessary for the long-term success of the unit

38. Discusses goals with individuals to be sure they are clear

39. Is able to answer almost any question about the work

40. Can find the resources to get things done

41. Applies pressure to get results

42. Immediately gives individuals credit for doing good work

43. Makes decisions based on the facts

44. Accepts constructive criticism

45. Involves workers in setting their own goals

46. Helps employees understand how their work relates to the organization's goals

47. Is approachable

48. Gets people to work as a team

49. Knows when to coach employees and when to leave them on their own

50. Is trusted by people in his/her unit

51. Makes plans that are clear

$\begin{array}{lllllll}\text { Never } & \text { Sometimes } & \text { Always } \\ 1 & 2 & 3 & 4 & 5 & 6 & 7 \\ 1 & 2 & 3 & 4 & 5 & 6 & 7 \\ 1 & 2 & 3 & 4 & 5 & 6 & 7 \\ & & & & & & \\ 1 & 2 & 3 & 4 & 5 & 6 & 7 \\ & & & & & & \\ 1 & 2 & 3 & 4 & 5 & 6 & 7 \\ & & & & & & \\ 1 & 2 & 3 & 4 & 5 & 6 & 7 \\ & & & & & & \\ 1 & 2 & 3 & 4 & 5 & 6 & 7 \\ 1 & 2 & 3 & 4 & 5 & 6 & 7 \\ 1 & 2 & 3 & 4 & 5 & 6 & 7 \\ 1 & 2 & 3 & 4 & 5 & 6 & 7 \\ 1 & 2 & 3 & 4 & 5 & 6 & 7 \\ & & & & & & \\ 1 & 2 & 3 & 4 & 5 & 6 & 7\end{array}$

$\begin{array}{lllllll}1 & 2 & 3 & 4 & 5 & 6 & 7\end{array}$

$\begin{array}{lllllll}1 & 2 & 3 & 4 & 5 & 6 & 7\end{array}$

$\begin{array}{lllllll}1 & 2 & 3 & 4 & 5 & 6 & 7\end{array}$

$\begin{array}{lllllll}1 & 2 & 3 & 4 & 5 & 6 & 7\end{array}$

$\begin{array}{lllllll}1 & 2 & 3 & 4 & 5 & 6 & 7\end{array}$

$\begin{array}{lllllll}1 & 2 & 3 & 4 & 5 & 6 & 7\end{array}$

$\begin{array}{lllllll}1 & 2 & 3 & 4 & 5 & 6 & 7\end{array}$

$\begin{array}{lllllll}1 & 2 & 3 & 4 & 5 & 6 & 7\end{array}$

$\begin{array}{lllllll}1 & 2 & 3 & 4 & 5 & 6 & 7\end{array}$

$\begin{array}{lllllll}1 & 2 & 3 & 4 & 5 & 6 & 7\end{array}$

$\begin{array}{lllllll}1 & 2 & 3 & 4 & 5 & 6 & 7\end{array}$

$\begin{array}{lllllll}1 & 2 & 3 & 4 & 5 & 6 & 7\end{array}$

$\begin{array}{lllllll}1 & 2 & 3 & 4 & 5 & 6 & 7\end{array}$

$\begin{array}{lllllll}1 & 2 & 3 & 4 & 5 & 6 & 7\end{array}$

$\begin{array}{lllllll}1 & 2 & 3 & 4 & 5 & 6 & 7\end{array}$

$\begin{array}{lllllll}1 & 2 & 3 & 4 & 5 & 6 & 7\end{array}$ 
Remember: Mark each statement "1" (never) to "7" (always) based on how accurately you feel it describes the person named on the front page.

\section{This person:}

52. Makes sure people know how their performance is being evaluated

53. Helps people learn new skills

\begin{tabular}{lllllll} 
Never & \multicolumn{2}{l}{ Sometimes } & \multicolumn{2}{c}{ Always } \\
1 & 2 & 3 & 4 & 5 & 6 & 7 \\
1 & 2 & 3 & 4 & 5 & 6 & 7 \\
& & & & & & \\
1 & 2 & 3 & 4 & 5 & 6 & 7 \\
1 & 2 & 3 & 4 & 5 & 6 & 7 \\
1 & 2 & 3 & 4 & 5 & 6 & 7 \\
1 & 2 & 3 & 4 & 5 & 6 & 7 \\
1 & 2 & 3 & 4 & 5 & 6 & 7 \\
& & & & & & \\
1 & 2 & 3 & 4 & 5 & 6 & 7 \\
1 & 2 & 3 & 4 & 5 & 6 & 7 \\
& & & & & & \\
1 & 2 & 3 & 4 & 5 & 6 & 7 \\
1 & 2 & 3 & 4 & 5 & 6 & 7 \\
1 & 2 & 3 & 4 & 5 & 6 & 7
\end{tabular}

54. Has a clear idea of the future direction of the unit

55. Sets high standards of performance

56. Gives frequent praise for good work

57. Supports teamwork in the group

58. Speaks effectively in front of a group

59. Is open to new ideas about getting the work done

60. Makes timely decisions

61. Instills people with the confidence to do their work

62. Is directive

$\begin{array}{lllllll}1 & 2 & 3 & 4 & 5 & 6 & 7\end{array}$

64. Effectively organizes and directs the work of employees

$\begin{array}{lllllll}1 & 2 & 3 & 4 & 5 & 6 & 7\end{array}$

65. Works to improve the competence of the people in his/her unit

$\begin{array}{lllllll}1 & 2 & 3 & 4 & 5 & 6 & 7\end{array}$

66. Allows people to do work the way they want as long as it is done correctly

67. Is self-confident

$\begin{array}{lllllll}1 & 2 & 3 & 4 & 5 & 6 & 7\end{array}$

$\begin{array}{lllllll}1 & 2 & 3 & 4 & 5 & 6 & 7\end{array}$

68. Makes sure people know the deadlines for accomplishing goals

$\begin{array}{lllllll}1 & 2 & 3 & 4 & 5 & 6 & 7\end{array}$

69. Encourages people to help each other

70. Is friendly

$\begin{array}{lllllll}1 & 2 & 3 & 4 & 5 & 6 & 7\end{array}$

$\begin{array}{lllllll}1 & 2 & 3 & 4 & 5 & 6 & 7\end{array}$

71. Informs people of the reasons for making changes in plans or goals

$\begin{array}{lllllll}1 & 2 & 3 & 4 & 5 & 6 & 7\end{array}$

72. Makes effective decisions

$\begin{array}{lllllll}1 & 2 & 3 & 4 & 5 & 6 & 7\end{array}$

73. Is dependable in dealing with people

$\begin{array}{lllllll}1 & 2 & 3 & 4 & 5 & 6 & 7\end{array}$

74. Gets his/her point across when talking

$\begin{array}{lllllll}1 & 2 & 3 & 4 & 5 & 6 & 7\end{array}$

75. Has the necessary technical skills to lead the unit

$\begin{array}{lllllll}1 & 2 & 3 & 4 & 5 & 6 & 7\end{array}$

76. Shows interest in suggestions from members of the work group

$\begin{array}{lllllll}1 & 2 & 3 & 4 & 5 & 6 & 7\end{array}$

77. Evaluates performance against agreedupon goals

$\begin{array}{lllllll}1 & 2 & 3 & 4 & 5 & 6 & 7\end{array}$

78. Makes sure people have the resources to do their jobs

$\begin{array}{lllllll}1 & 2 & 3 & 4 & 5 & 6 & 7\end{array}$

79. Sets clear standards against which performance is measured

$\begin{array}{lllllll}1 & 2 & 3 & 4 & 5 & 6 & 7\end{array}$ 
Remember: Mark each statement "1" (never) to "7" (always) based on how accurately you feel it describes the person named on the front page.

This person:

80. Displays confidence under pressure

81. Communicates effectively in writing

82. Sets realistic goals

83. Uses plans to manage

84. Keeps up-to-date on technical developments in his/her field
Never Sometimes Always

$\begin{array}{lllllll}1 & 2 & 3 & 4 & 5 & 6 & 7\end{array}$

$\begin{array}{lllllll}1 & 2 & 3 & 4 & 5 & 6 & 7\end{array}$

$\begin{array}{lllllll}1 & 2 & 3 & 4 & 5 & 6 & 7\end{array}$

$\begin{array}{lllllll}1 & 2 & 3 & 4 & 5 & 6 & 7\end{array}$

$\begin{array}{lllllll}1 & 2 & 3 & 4 & 5 & 6 & 7\end{array}$

Published by:

Pfaff and Associates

6667 Pleasantview

Portage, Michigan 49024

www.pfaffconsulting.com 